\title{
Detecting remotely triggered temporal changes around the Parkfield section of the San Andreas fault*
}

\author{
Peng Zhao ${ }^{1, *}$ Zhigang Peng $^{1}$ and Karim Ghazi Sabra ${ }^{2}$ \\ ${ }^{1}$ School of Earth and Atmospheric Science, Georgia Institute of Technology, Atlanta, GA 30338, USA \\ ${ }^{2}$ School of Mechanical Engineering, Georgia Institute of Technology, Atlanta, GA 30338, USA
}

\begin{abstract}
Detecting temporal changes in fault zone properties at seismogenic depth have been a long-sought goal in the seismological community for many decades. Recent studies based on waveform analysis of repeating earthquakes have found clear temporal changes in the shallow crust and around active fault zones associated with the occurrences of large nearby and teleseismic earthquakes. However, repeating earthquakes only occur in certain locations and their occurrence times cannot be controlled, which may result in inadequate sampling of the interested regions or time periods. Recent developments in passive imaging via auto- and cross-correlation of ambient seismic wavefields (e.g., seismic noise, earthquake coda waves) provide an ideal source for continuous monitoring of temporal changes around active fault zones. Here we conduct a systematic search of temporal changes along the Parkfield section of the San Andreas fault by cross-correlating relatively high-frequency $(0.4-1.3 \mathrm{~Hz})$ ambient noise signals recorded by 10 borehole stations in the High Resolution Seismic Network. After using stretch/compressed method to measure the delay time and the decorrelation-index between the daily noise cross-correlation functions (NCCFs), we find clear temporal changes in the median seismic velocity and decorrelation-index associated with the 2004 M6.0 Parkfield earthquake. We also apply the same procedure to the seismic data around five regional/teleseismic events that have triggered non-volcanic tremor in the same region, but failed to find any clear temporal changes in the daily NCCFs. The fact that our current technique can detect temporal changes from the nearby but not regional and teleseismic events, suggests that temporal changes associated with distance sources are very subtle or localized so that they could not be detected within the resolution of the current technique $(\sim 0.2 \%)$.
\end{abstract}

Key words: temporal changes; remote triggering; seismic noise; cross-correlation; interferometry; seismic coda CLC number: P315.3 Document code: A

\section{Introduction}

Measuring temporal variations within active fault zones (FZs) has been an ongoing challenge within earthquake sciences for decades. An improved understanding of temporal changes in FZ properties has important implications for many aspects of earthquake physics, including long-term evolutions of FZ structures, earthquake and fault interaction, and seismic hazard mitigation. Many early studies of temporal changes based on travel times from natural earthquakes or scat-

\footnotetext{
* Received 27 May 2010; accepted in revised form 10 August 2010; published 10 October 2010 .

* Corresponding author. e-mail: pzhao@gatech.edu

(C) The Seismological Society of China and Springer-Verlag Berlin Heidelberg 2010
}

tering properties of coda waves were generally not convincing, mostly because of the mixing of spatial variations in the source with actual temporal changes occurring in the medium (e.g., Liu et al., 2004; Peng and Ben-Zion, 2005). Recent studies based on waveform analysis of repeating earthquakes or repeatable controlled sources have found clear temporal changes of seismic velocities in shallow surface layers and around active FZs associated with the occurrences of nearby major earthquakes (e.g., Poupinet et al., 1984; Li et al., 1998, 2006; Matsumoto et al., 2001; Vidale and Li, 2003; Niu et al., 2003, 2008; Schaff and Beroza, 2004; Rubinstein and Beroza, 2004a, b, 2005; Peng and Ben-Zion, 2006; Rubinstein et al., 2007a; Silver et al., 2007; Taira et al., 2008; Chao and Peng, 2009; Zhao and Peng, 2009). The observed temporal changes in seismic 
velocities during strong ground motions of large earthquakes are generally small (a few percent), and are followed by logarithmic recoveries on the time scales of several months to years. The observed temporal changes could be related to the nonlinear response in the shallow crust (Sawazaki et al., 2006; Rubinstein, 2010; Wu et al., 2010) and around active FZs (Wu et al., 2009) caused by strong ground motions of local large earthquakes.

While these studies mostly focus on temporal changes caused by earthquakes in the near field (i.e., within 1-2 fault rupture lengths), a recent study based on waveform analysis of repeating earthquakes has observed clear temporal changes around the Parkfield section of the San Andreas fault (SAF) induced by the dynamics stresses from the surface waves of the $2004 M_{\mathrm{W}} 9.2 \mathrm{Su}-$ matra and the $1992 M_{\mathrm{W}} 7.3$ Landers earthquakes (Taira et al., 2009). They suggested that large earthquakes like the 2004 Sumatra earthquake could produce a global change of the Earth's fault systems, and such temporal changes may explain long-range temporal clustering of global seismicity (e.g., Kanamori, 1977; Mogi, 1979; Parsons, 2002). This is also consistent with recent observations of remotely triggered earthquakes (e.g., Hill et al., 1993; Gomberg et al., 2001, 2004; Hough and Kanamori, 2002; Prejean et al., 2004; Hill and Prejean, 2007; Velasco et al., 2008; Jiang et al., 2010) and non-volcanic tremor (Rubinstein et al., 2007b, 2009; Gomberg et al., 2008; Miyazawa and Brodsky, 2008; Miyazawa et al., 2008; Peng and Chao, 2008; Peng et al., 2008, 2009; Guilhem et al., 2010) following the occurrences of large shallow earthquakes. In particular, several recent studies have found that many large regional and teleseismic events in the past ten years, including the 2004 Sumatra earthquake, have triggered clear tremor around the Parkfield section of the SAF (Peng et al., 2008, 2009; Guilhem et al., 2010). It is still not clear whether other large earthquakes besides the Sumatra event also cause temporal changes around Parkfield.

Johnson and Jia (2005) recently performed laboratory dynamic experiments on granular media, and found that seismic waves could reduce the shear modulus and weaken the fault further, resulting in triggered brittle failure. Their results suggested that dynamically weakened FZ could produce both triggered seismic activity and temporal changes in material properties that are in principle observable through seismic methods. Because repeating earthquakes only occur in certain locations and their occurrence times cannot be controlled, this may result in inadequate or poor sampling of the inter- ested regions or time periods. The aforementioned Sumatra case (Taira et al., 2009) is rather unique because of the occurrence of the $2004 M_{\mathrm{W}} 6.0$ Parkfield earthquake, which has changed the occurrence pattern of many sets of repeating clusters (Lengliné and Marsan, 2009) and hence provides enough sampling points around the subsequent Sumatra earthquake. However, repeating earthquakes may not be enough to detect temporal changes associated with other teleseismic events that occurred either before or long after the 2004 Parkfield earthquake.

Recent developments in passive imaging via autoand cross-correlating of ambient seismic wavefields provide an exciting opportunity for mapping spatiotemporal variations of the Earth's properties with unprecedented temporal and spatial resolutions (e.g., Sabra et al., 2005a, b, 2006; Shapiro et al., 2005; Gerstoft et al., 2006; Sens-Schönfelder and Wegler, 2006; Brenguier et al., 2008a, b; Ohmi et al., 2008; Wegler et al., 2009; Xu and Song, 2009; Chen et al., 2010; Cheng et al., 2010). The basic idea is that cross-correlation or deconvolution of diffuse seismic wavefields (e.g., ambient seismic noises, earthquake coda waves) recorded at two stations results in the empirical Green's function (EGF) between them. Because ambient wavefields exist at all the time in many regions, they provide an ideal source for continuous monitoring of the temporal changes of material properties in the upper crust. However, for most applications, the actual ambient vibration fields recorded on the structure of interest will not likely be fully diffuse. In this case, there is no formal guarantee that the noise cross-correlation function (NCCF), or the EGF, would yield an unbiased estimate of the actual Green's function. But if the goal is to just passively monitor the Earth's properties using this cross-correlation technique (e.g., for FZ monitoring), then the only condition is the relative temporal stability of the ambient noise source, even if the NCCF waveform differs from the actual Green's function (Hadziioannou et al., 2009).

Brenguier et al. (2008b) applied this technique to the Parkfield region and detected a clear reduction of seismic velocities in the Parkfield section of the SAF associated with the $2003 M_{\mathrm{W}} 6.5$ San Simeon and the $2004 M_{\mathrm{W}} 6.0$ Parkfield earthquakes. Motivated by their success, here we apply the same technique to examine the temporal changes associated with several large regional and teleseismic events that have triggered tremor around Parkfield (Peng et al., 2008, 2009; Guilhem et al., 2010). Because we expect that the temporal changes associated with teleseismic events would be subtle and 
probably transient, we use slightly higher frequency bands $(0.4-1.3 \mathrm{~Hz})$ that are more sensitive to subtle changes, and do not use the 30-day smooth window as done in the previous study (Brenguier et al., 2008b). We also apply the same technique around the 2003 San Simeon and the 2004 Parkfield earthquakes to prove its effectiveness. In the next two sections, we first introduce the analysis procedure to compute the daily EGF, followed by the methods to measure temporal changes. The results are presented in section 4 and further discussed in section 5 .

\section{Data and analysis procedure}

The San Andreas fault (SAF) is a right-lateral strike-slip fault that extends approximately $1200 \mathrm{~km}$ along the boundary between the Pacific and the North American plates. The Parkfield section of the SAF straddles the transition between the creeping segment of the fault to the NW and the locked segment to the SE (Figure 1). This region is well instrumented and studied, mostly due to the Parkfield earthquake prediction experiment project (Bakun and Lindh, 1985) and the recent San Andreas fault observatory at depth (SAFOD) experiment (Hickman et al., 2004). In this work, we use the continuous seismic data recorded at the High Resolution Seismic Network (HRSN) around the Parkfield section of the SAF to compute the daily EGF. The HRSN is composed of 13 borehole stations with depth ranges from about $60 \mathrm{~m}$ to $600 \mathrm{~m}$ below the surface, and is recorded in continuous mode since 2001 . We use the

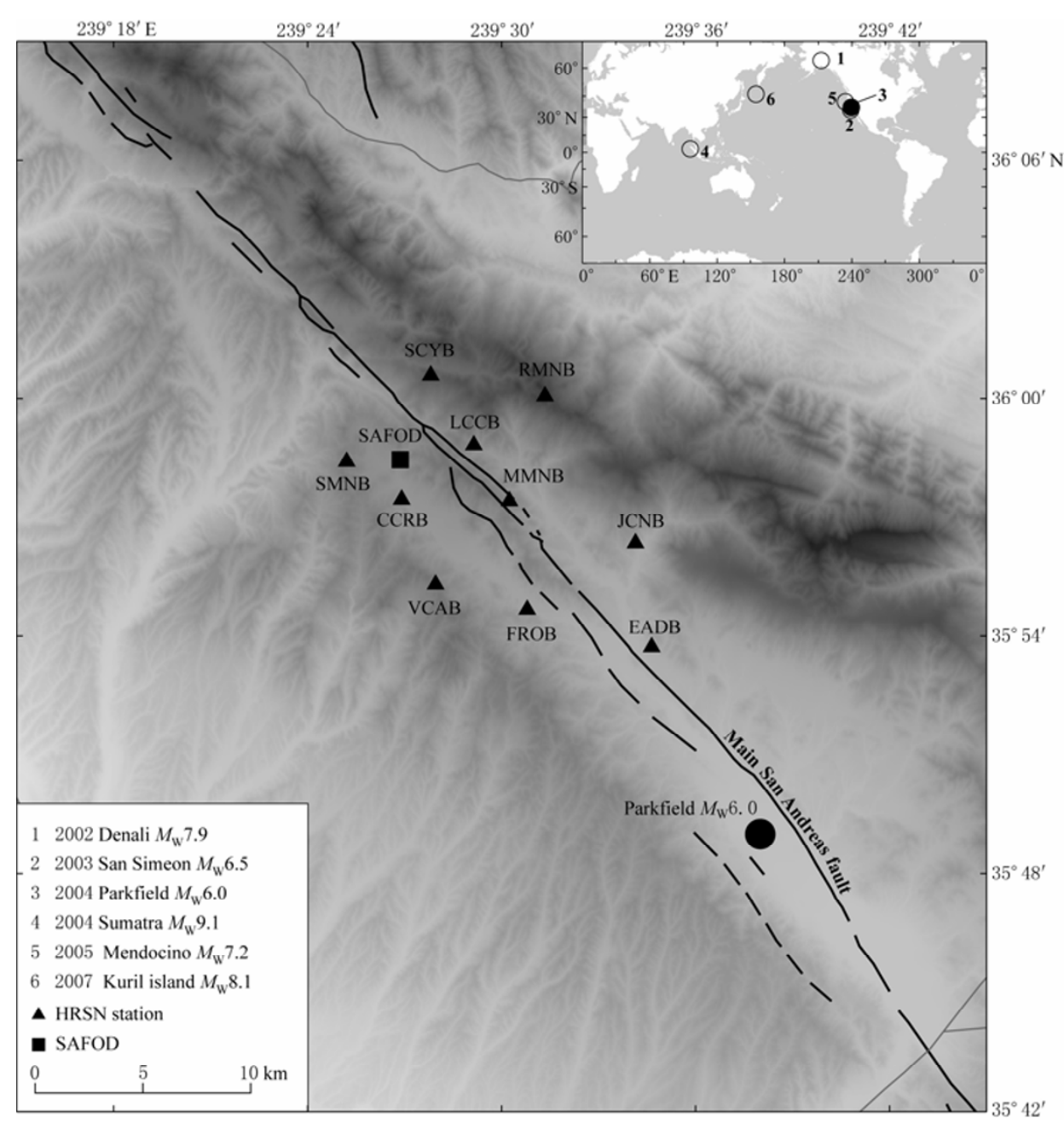

Figure 1 (a) A map of the Parkfield section of the San Andreas fault. The epicenter of the 2004 M6.0 Parkfield earthquake is marked with solid circle. The thick lines denote surface traces of faults. Triangles mark the locations of 10 seismic stations of High Resolution Seismic Network (HRSN) used in this study. The background is shaded topography with white being low and dark being high. The inset shows a map of the world with the epicentral locations of six earthquakes. The name of each earthquake is labeled on left bottom of the figure. SAFOD: San Andreas fault observatory at depth. 
20 samples/s data recorded at the 10 borehole stations (excluding JCSB, VARB, and GHIB). Stations JCSB and VARB have different instrument response from the rest stations. In addition, the computed EGFs between station GHIB and the other stations are not very stable, probably because of the relatively large inter-station distance that is perpendicular to the noise propagation direction from the coastline (Sabra et al., 2005a). Hence, we only focus on the rest 10 stations that are located nearby with the same instrument response. Although the examined frequency range $(0.4-1.3 \mathrm{~Hz})$ is slightly below the corner frequency of the instrument response $(\sim 2$ $\mathrm{Hz}$ ), we did not correct the instrument response to avoid producing artifacts from the deconvolution procedure.

In this study we focus on the four regional and teleseismic events that have triggered tremor in the same region (Peng et al., 2008, 2009; Guilhem et al., 2010). These include the $2002 M_{\mathrm{W}} 7.9$ Denali fault, $2004 M_{\mathrm{W}} 9.1$ Sumatra, $2005 M_{\mathrm{W}} 7.2$ Mendocino, and $2007 M_{\mathrm{W}} 8.1 \mathrm{Ku}-$ ril island earthquakes. These events are chosen because they produce among the largest peak ground velocities (PGVs) in the study region (Guilhem et al., 2010). In addition, we also examine data around the 2003 San Simeon and 2004 Parkfield earthquakes to test the robustness of our method.

The analysis procedure generally follows that of Brenguier et al. (2008b) and is briefly described here. First, we download the seismic data recorded at those 10 seismic stations two months before and after the occurrence date of these six events. The continuous records are then cut into one-day-long data, and band-pass filtered from $0.4 \mathrm{~Hz}$ to $1.3 \mathrm{~Hz}$. This frequency band is close to the frequency range of the $\mathrm{P}$-wave seismic noise in the Parkfield region driven by distant ocean winds (Zhang et al., 2009, 2010), and is slightly higher than that of the typical microseism band of $0.1-0.2 \mathrm{~Hz}$ and the range of $0.1-0.9 \mathrm{~Hz}$ used by the previous study (Brenguier et al., 2008b). We choose the slightly higher frequency range because of their relative stability within a short time range (Zhang et al., 2009) and their potential of detecting subtle temporal changes with short inter-station distances.

After the filtering process, we use a constant threshold to reduce the effect of large events and spurious instrument noises. The threshold at each station is calculated as the median value of the standard deviations of the daily-long seismic records within two months for each event. Any data point with amplitude larger than the threshold was assigned the threshold value. We also tested different values of the threshold and found that the obtained daily EGFs are not very sensitive to such choice. Next, we compute the fast Fourier transform (FFT) and whiten the spectrum in the frequency domain (Brenguier et al., 2008a, b). Finally, we cross-correlate the whitened spectrum between all possible station pairs in the frequency domain and then compute the inverse FFT to obtain the daily EGF in the time domain.

Figure 2 illustrates an example of daily EGFs between stations CCRB and MMNB two months before and after the 2004 Parkfield earthquake. Except for a few days, the obtained daily EGFs show high similarities up to $20 \mathrm{~s}$, suggesting that they are stable enough for measuring temporal changes.

\section{Measuring temporal changes from EGFs}

To simplify the next analysis step, we consider the two-month daily EGFs around each target event as an individual group. For a pair of stations within each group, we first stack all daily EGFs and use that as the reference trace (Figure 2). Next, we select daily EGFs with relative high quality by removing the daily EGFs with the correlation coefficient to the reference trace less than 0.7 or the signal-to-noise ratio (SNR) less than 3 . The correlation is calculated with a 20 -s time window starting from $-10 \mathrm{~s}$ and the SNR is calculated using a 20 -s time window with signals starting from $-10 \mathrm{~s}$ and noises from $65 \mathrm{~s}$. Because the estimated apparent velocity for the direct waves is about $5 \mathrm{~km} / \mathrm{s}$ (Zhang et al., 2009), and all inter-station distances are less than $20 \mathrm{~km}$, a 20-s time window used for the calculation of correlation and SNR captures most of seismic energy for the direct waves with large amplitudes (e.g., Figure 2).

After the selection process, we measure the subtle changes between these daily EGFs and the reference within a fixed time window (Wegler et al., 2009). The beginning of each time window is set to be $\pm l / v$, where $l$ is the inter-station distance and $v$ is the assumed seismic velocity, and the plus and minus signs correspond to the positive and negative time axis, respectively. The velocity is set to be $2.5 \mathrm{~km} / \mathrm{s}$, which is lower than the direct P-wave velocity in this region (Zhang et al., 2009). In this way, the direct arrivals of the EGFs, which is more affected by seasonal variations (Brenguier et al., 2008b), are not included in measuring temporal changes. The length of the time window is determined based on a 


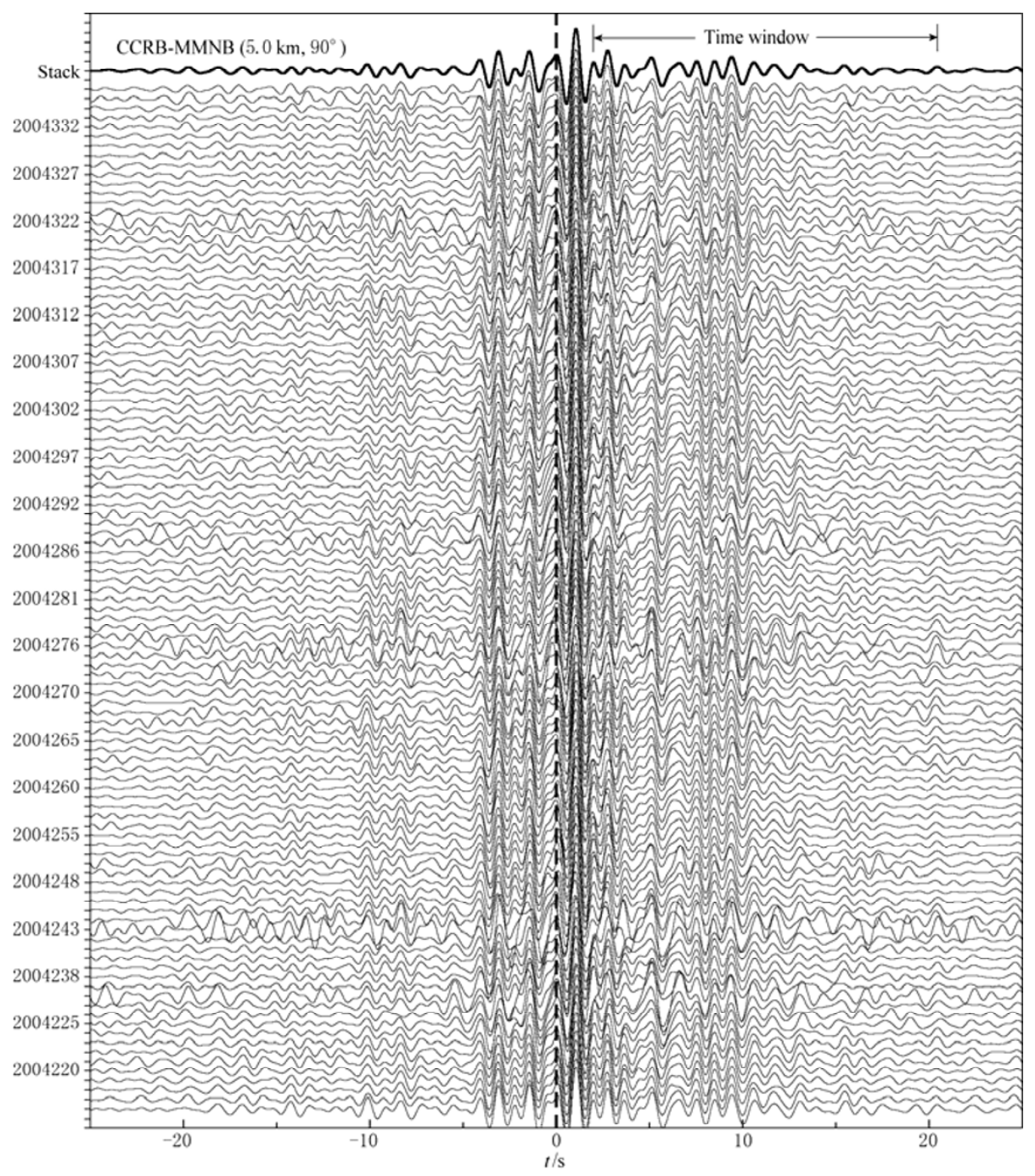

Figure 2 Waveforms of the daily empirical Green's functions between the station pair CCRB and MMNB two months before and after the $2004 M_{\mathrm{W}} 6.0$ Parkfield earthquake. The corresponding date of waveforms is labeled in the left (4-digit-year, 3-digit-Julian day) and the stacked reference trace is shown on the top in thick line. The vertical dashed line marks the time zero, and two broken bars indicate the time window to calculate the temporal changes, respectively. Inter-station distance and azimuth are labeled on the top.

data-adaptive method using the correlation index $d$ for a pair of stations as

$$
d=\frac{\left(\sum s(t)\right)^{2}}{N \sum s^{2}(t)},
$$

where $s(t)$ is the daily EGF, and $N$ is the total number of daily EGFs. A large correlation index corresponds to the portion of waveforms with high similarity and large SNR. In this study, we choose the time window with the correlation index $d$ larger than 0.9 .

After selecting the time window for each station pair, we employ a so-called stretch/compression method to measure the temporal changes. The method treats the daily EGF as the stretched or compressed version of the reference waveform (Poupinet et al., 1984; Snieder et al., 2002; Brenguier et al., 2008b; Wegler et al., 2009). The percentage of seismic velocity change is calculated from the slope of time delay/advance $(\mathrm{d} t) v s$. time $(t)$ as

$$
\frac{\mathrm{d} v}{v}=-\frac{\mathrm{d} t}{t}
$$

Following Wegler et al. (2009), each daily EGF was stretched and compressed using a grid search with 10000 trials between $-3 \%$ and $3 \%$ to estimate the parameter $\mathrm{d} v / v$ from equation (2). For each trial of the grid 
search, we computed the correlation coefficient $R$ between the reference trace and the stretched or compressed daily EGF in the fixed time window as discussed before. The best-fitting velocity change is assigned to be the one associated with the largest $R$ (Figure 3 ). In addition, we compute the decorrelation index each day, which is defined as $1-R$ (Niu et al., 2003; Peng and Ben-Zion, 2006), and use it to quantify the difference relative to the reference trace. Finally, we compute the median value of the velocity changes and the decorrelation indexes from all possible station pairs (with a minimum of 10 pairs) each day, and use them as a measure of daily temporal changes in our study region.
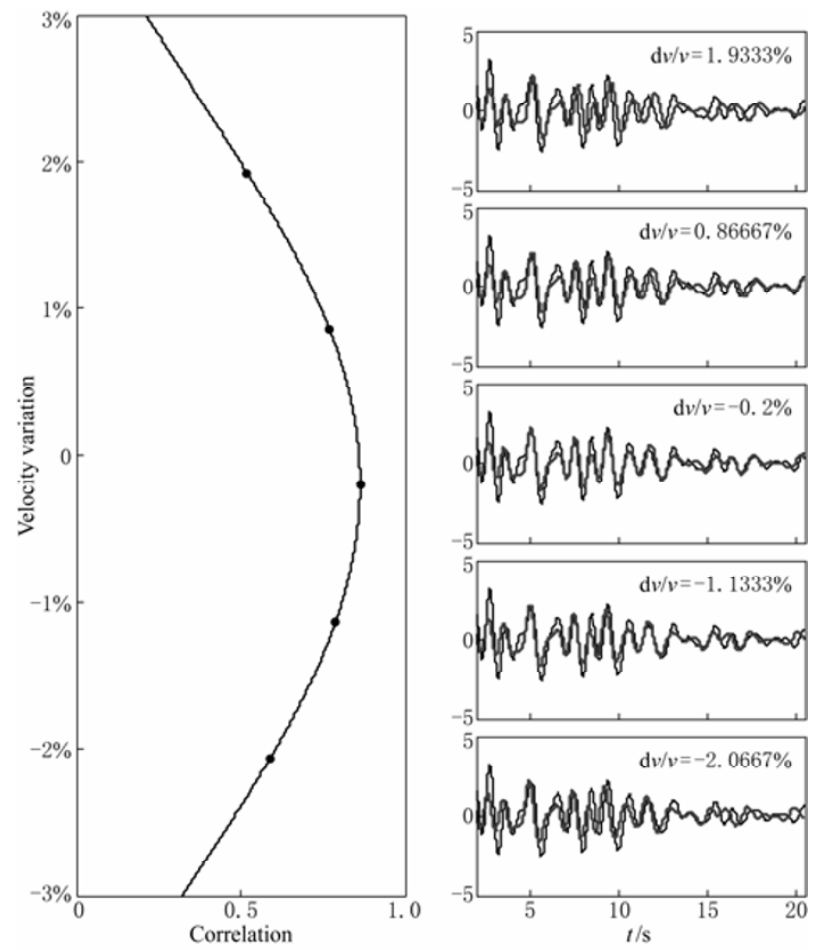

Figure 3 An illustration of the stretch/compression method for the seismic trace on date 2004277 within the time window as shown in Figure 2. The correlation value between the reference and each stretched/compressed daily EGF is plotted on the left. Thin traces on the right are the reference trace and gray ones represent the stretched or compressed version of daily EGF with the corresponding percentage shown on the top of each panel and marked as the solid circle in the left panel.

\section{Results}

The median velocity changes and decorrelation index are plotted at the corresponding day for detecting temporal changes associated with each target event. Figure 4 shows the result for the 2003 San Simeon and
2004 M6.0 Parkfield earthquakes. Clear reduction of seismicity velocity (up to $-0.4 \%$ ) is observed immediately after the 2004 mainshock (Figure 4a), followed by a faster recovery in the first few days and a smaller recovery at later times. The results from the median decorrelation index also show a sudden increase immediately after the Parkfield mainshock. However, the decorrelation index recovers to the pre-mainshock within the next 1-2 days, faster than the recovery of the seismic velocity changes. In both cases, the largest change is shown not at the same day as the Parkfield mainshock, mostly likely because the mainshock occurred later on that day (2004-09-28 17:57 UTC). Hence the averaged temporal changes on that day are smaller than the following day. Moreover the median absolute deviations (MAD) of velocity changes right after the 2004 event are significantly larger than that of other days (Figure 4a), suggesting a larger spatial variation of temporal changes for different station pairs after the Parkfield mainshock. In addition to the co-seismic changes associated with the Parkfield mainshock, there are also clear changes in both the velocity change and decorrelation indexes at a few other days, for example, around 18 days after the mainshock. We have examined nearby and global seismicity, local tremor activity (Nadeau and Guilhem, 2009) and precipitation, but failed to find any correlation with the changes around that day. For the 2003 San Simeon earthquake, we did not observe clear systematic changes in seismic velocity, but we found an increase of decorrelation index after the mainshock (Figure 4d). However, a three-day data gap following the San Simeon mainshock makes it difficult to determine whether there is clear co-seismic change associated with this event or not.

As mentioned above, an important condition to detect reliable temporal changes is the temporal stability of noise sources (Hadziioannou et al., 2009). Among these six events we investigated, the 2004 Parkfield earthquake are followed by numerous aftershocks in our study region that could cause a transient change in the noise sources. To remove the possible influence from these aftershocks, we mute earthquake signals from band-passed seismograms (i.e., $0.4-1.3 \mathrm{~Hz}$ ) two months before and after the 2004 events. We first compute arrival times of direct $\mathrm{P}$ waves for all earthquakes listed in the relocated catalog of Thurber et al. (2006) based on a 1-D velocity model in central and northern California (Waldhauser et al., 2004). The length of the time window $T$ to be set as zero is assigned to be $200 \mathrm{~s}$ starting 

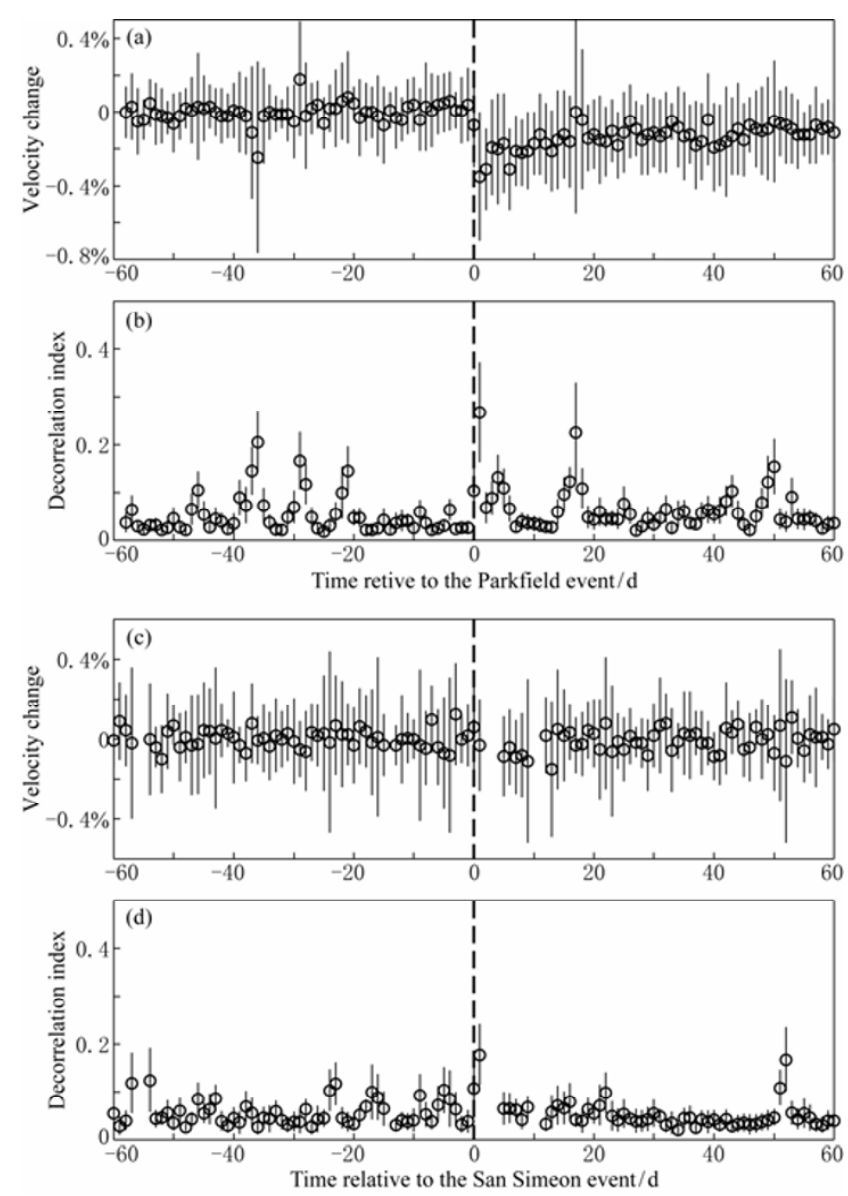

Figure 4 (a) Median velocity changes from all possible station pairs versus the occurrence dates relative to the $2004 M_{\mathrm{W}} 6.0$ Parkfield earthquake (the vertical black dashed line). (b) Median value of decorrelation index versus the occurrence dates relative to the $2004 M_{\mathrm{W}} 6.0$ Parkfield earthquake. (c) Median velocity changes versus the occurrence dates relative to the 2003 San Simeon earthquake. (d) Median value of decorrelation index versus the occurrence dates relative to the 2003 San Simeon earthquake. The vertical short black lines in each panel represent the median absolute deviations (MADs) of measurement each day. In all four panels, we did not show the daily median values if the available number of station pairs is less than 10 on that day.

$5 \mathrm{~s}$ before the predicted $\mathrm{P}$ arrivals for earthquakes with magnitudes larger than 3.5. Otherwise, it is calculated using following equations based on their coda-duration magnitude $M$ (Lee et al., 1972; Bakun, 1984):

$$
T=10^{(M+0.87-0.00354) / 2},
$$

where $\Delta$ is the epicenter distance in kilometers. A cosine taper is applied to on each side of a time-window with $5 \%$ of the entire width of the window. After this procedure, the seismic signals generated by nearby aftershocks have been mostly removed, with about $11 \%$ and
$9 \%$ of daily seismograms being muted on the first and following days of the mainshock, respectively.

Figure 5 illustrates the difference of estimated temporal changes after the 2004 Parkfield earthquake with and without aftershocks being muted. The general patterns are similar, except that the values of the decorrelation indexes are somehow smaller after removing those aftershocks, especially for the first two days after the mainshock. In addition, the most significant difference for the velocity change is that the value at the first day following the mainshock is reduced from $-0.7 \%$ to $-0.4 \%$ after muting aftershocks. However, we still observe clear co-seismic changes, followed by gradual post-seismic recoveries. This also suggests that without muting aftershocks, the change of noise sources (i.e., from aftershocks) could be potentially mapped into estimated temporal changes.

Figure 6 shows the median velocity changes associated with four regional and teleseismic events that have triggered tremor in the study region. The obtained results show strong fluctuations of velocity changes, especially for the 2002 Denali earthquake, which might be caused by the relatively low SNR before an increase
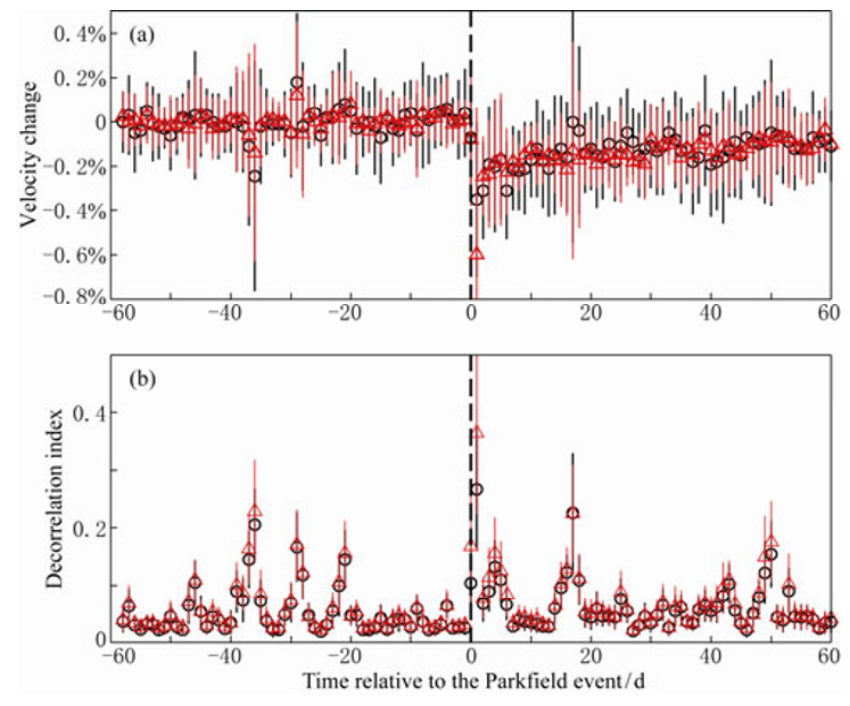

Figure 5 A comparison of the median velocity changes (a) and median decorrelation indexes (b) around the 2004 M6.0 Parkfield earthquake before and after muting earthquakes listed in the relocated catalog of Thurber et al. (2006). The black circles and red triangles mark the estimated median velocity changes with and without removing aftershocks, respectively. Their corresponding median absolute deviations are represented by vertical short black and red lines, respectively. The vertical black dashed line marks the occurrence date of the 2004 Parkfield event. 
of the pre-amplification gain for the HRSN in 2003 (Brenguier et al., 2008b). In addition, no clear temporal changes in the median velocity changes are observed during the occurrence of these regional and teleseismic events, except a weak velocity drop for a few days after the 2004 Sumatra earthquake. In addition, the change did not happen until two days after this event (Figure $6 b)$. However, there is a data gap in the first few days after the 2004 event, which is mainly caused by power outage due to a bad local weather (R. Nadeau, personal
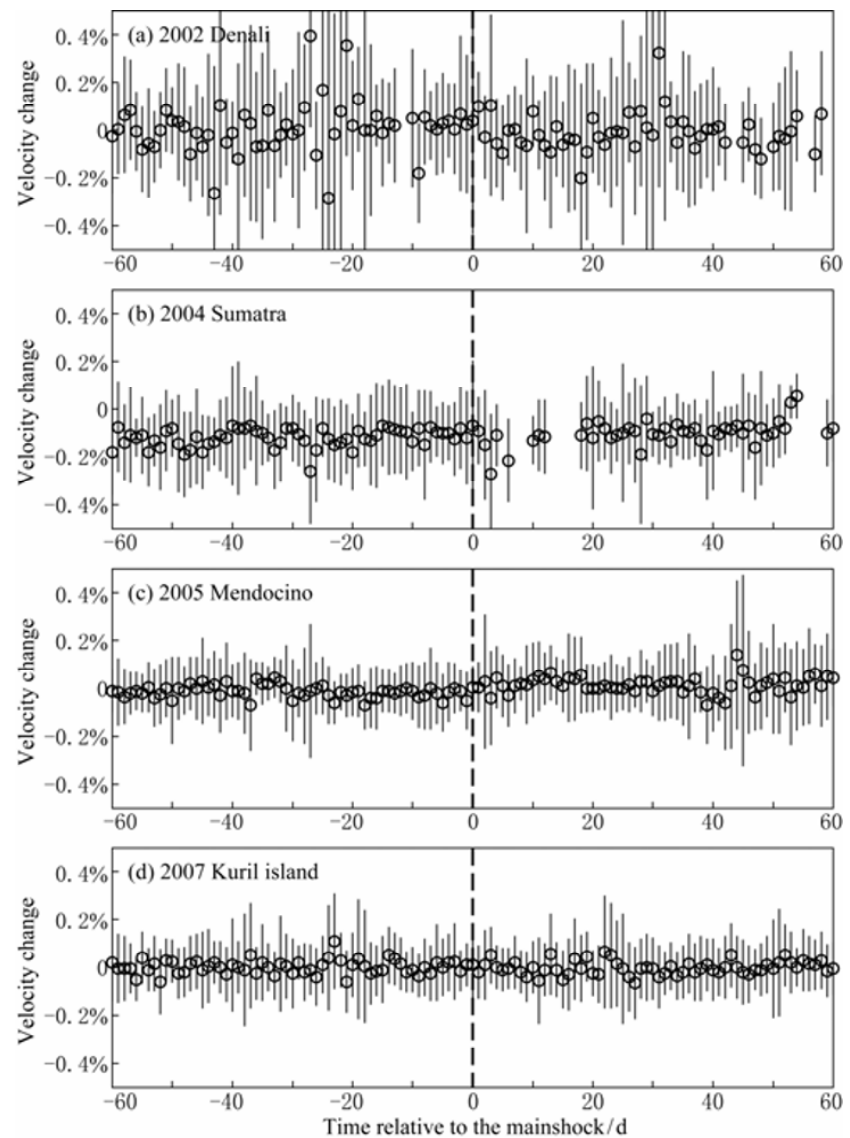

Figure 6 Temporal changes in the median velocity changes associated with the four regional/teleseismic events. The name of corresponding event is labeled on the top left corner of each panel. Other symbols are the same as Figure 4a.

\section{Discussion and conclusions}

In this study, we applied the recent developed noise cross-correlation technique to detect temporal changes around the Parkfield section of the San Andreas fault (SAF) associated with four regional and teleseismic events that have triggered tremor in the same region. However, within the resolution of the current technique, communication, 2008), making it difficult to track the co-seismic velocity changes. The median decorrelation index shows a subtle increase around or immediately after the 2002 Denali, 2004 Sumatra, and 2005 Mendocino events (Figure 7). However, similar or even larger changes are observed at other times in each case. Hence, we conclude that the results obtained from our current methodology employed in this article did not reveal any clear and systematic changes associated with these regional and teleseismic events.
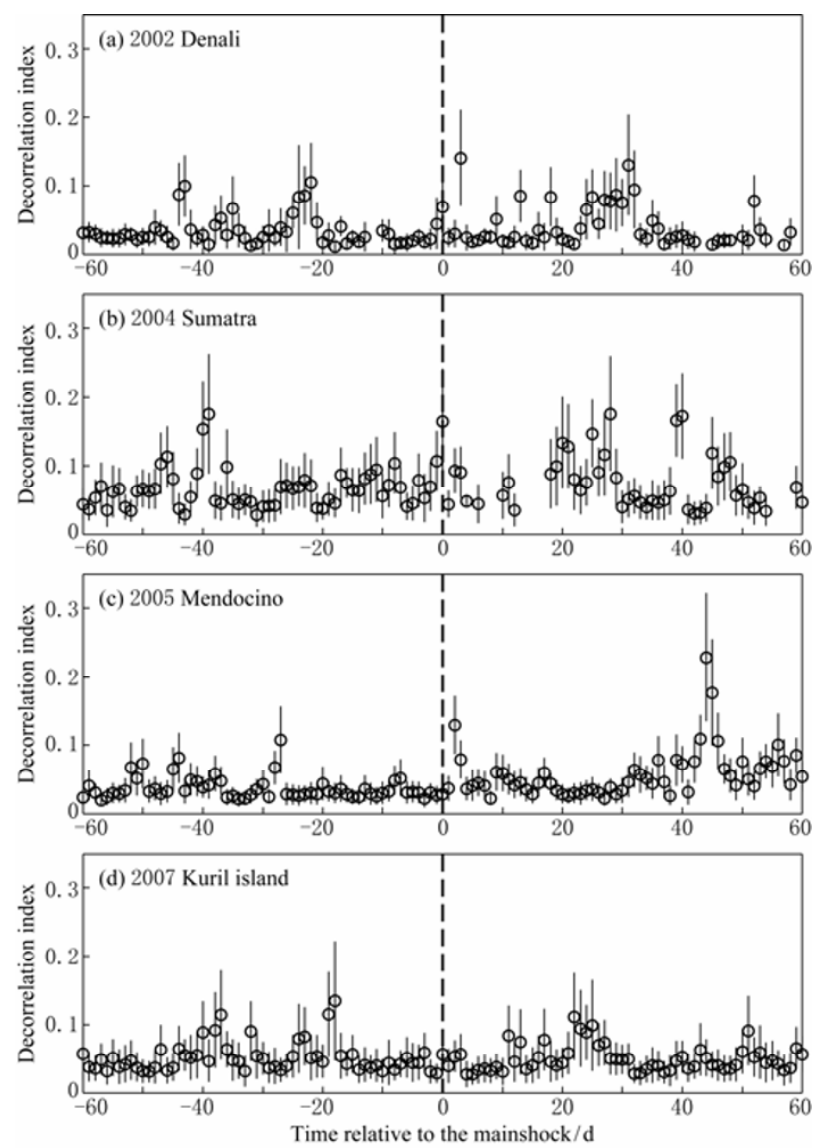

Figure 7 Temporal changes in the median decorrelation indexes associated with the four regional/teleseismic events. The name of corresponding event is labeled on the top left corner of each panel. Other symbols are the same as Figure $4 \mathrm{~b}$.

which is $\sim 0.2 \%$ based on the average error estimate of the velocity changes, we were unable to detect any clear changes associated with these regional and teleseismic events. There are two possible explanations for such 'negative' results. One is that these events are too far to cause any temporal changes. The second is that temporal changes did occur, but are undetected by the current technique. We favor the second explanation for the fol- 
lowing reasons.

First, recent studies based on spectral ratio analysis between borehole and surface strong ground motion recordings have shown that modest ground motions on the order of a few tens of $\mathrm{cm} / \mathrm{s}^{2}$ or less (dynamic strain on the order of $10^{-5}$ ) are able to cause small but observable temporal changes in the shallow crust, resulting in nonlinear site response (Wu et al., 2010; Rubinstein, 2010). The peak ground velocities associated with these regional and teleseismic events are in the range of $0.1-1$ $\mathrm{cm} / \mathrm{s}$, which correspond to the dynamic strain of $3 \times 10^{-7}-3 \times 10^{-6}$, slightly smaller than the aforementioned threshold for nonlinear ground motion. However, nonlinear effects have been identified in laboratory studies of geomaterials under strains as low as $10^{-8}$ (TenCate et al., 2004). These results suggest that the regional and teleseismic events could have the potential of causing nonlinear response and small temporal changes in the shallow crust. Other supporting evidence includes hydrological responses (i.e., changes of water table and surface water flows) and eruptions of volcanoes/geysers associated with large nearby and teleseismic earthquakes (e.g., Roeloffs, 1998; Manga and Brodsky, 2006; Manga and Wang, 2007; Wang et al., 2009). Among these studies, Roeloffs (1998) reported coseismic water level rises in a well near Parkfield, California, in response to three local and five distant earthquakes. The changes generally lasted for days or weeks, and were suggested to be the consequence of increase of coseismic pore pressure near the well. Brodsky et al. (2003) proposed that strong shaking from nearby earthquakes, or large surface waves from teleseismic events, may unclog pre-existing fractures in the shallow crust, resulted in increasing permeability and fluid flow. Finally, as mentioned before, Taira et al. (2009) have found clear changes of deep scatterer and fault zone strength associated with the 2004 Sumatra earthquake based on abundant repeating earthquakes in the same region. All these studies support our interference that large regional and teleseismic events could cause temporal changes around active fault zones.

To test the robustness of the technique, we also applied it to the 2003 San Simeon and 2004 Parkfield earthquakes and only found clear temporal changes in both the seismic velocities and decorrelation indexes for the 2004 Parkfield earthquake. This is consistent with recent studies in the same region based on waveform analysis of repeating earthquakes (Rubinstein and Beroza, 2005; Li et al., 2006; Taira et al., 2008), re- peatable control sources ( $\mathrm{Li}$ et al., 2006), receiver functions (Audet, 2010), and noise cross-correlation technique (Brenguier et al., 2008b). However, the reduction in seismic velocity in our study $(\sim 0.4 \%)$ is larger than that measured from Brenguier et al. (2008b) $(\sim 0.06 \%)$, but less than those $(\sim 1 \%-4 \%)$ from repeating earthquakes (e.g., Li et al., 2006). The difference with Brenguier et al. (2008b) mainly stems from their use of 30-day stacking of the daily EGF, which could significantly smooth the co-seismic changes. Similarly, the value of $0.4 \%$ obtained in this study is from the one-day average, while individual repeating earthquakes could sample larger temporal changes immediately after the mainshock.

The relationships between triggered earthquakes and tremor and triggered temporal changes are still not clear at this stage. The fact that our current technique can detect temporal changes for the nearby 2004 Parkfield earthquake but not for other regional and teleseismic events, suggests that temporal changes associated with regional and teleseismic events could be very small, i.e., less than the detection ability of our current technique $(\sim 0.2 \%)$. This sensitivity can be improved by enhancing the spatial directivity of this cross-correlation process. Indeed, the aforementioned variations in locations of noise sources could result in the change of waveforms of EGFs (Marzorati and Bindi, 2008), which could be mapped into temporal changes in the medium. To overcome this problem, many studies use the seismic noise records up to tens of days to balance the distribution of noise sources (e.g., Brenguier et al., 2008b; Xu and Song, 2009). Although this procedure will apparently reduce the resolution of detected temporal changes, it might improve the stability of the observation and we will test it in a follow-up study. In addition, future investigations are planned to assess the use of array analysis (e.g., Rost and Thomas, 2002) to select noise sources coming from certain regions before computing EGFs.

It is worth pointing out that most of the triggered tremor did not occur around Parkfield where most of the HRSN stations are located, but further south near Cholame and north in the creeping section of the SAF (Peng et al., 2009). Hence, the station coverage may not be ideal to detect temporal changes associated with the triggered activity. It is also possible that temporal change is localized in certain regions (e.g., high fractural densities or high-fluid pressures). Because we computed the median value of the velocity changes and the decorrelation indexes, this procedure is most sensitive to uni- 
form changes in the medium and could average out potential localized changes. In this case, focusing on the change of a particular phase, similar to that of Niu et al. (2003) and Taira et al. (2009), could help to identify the localized temporal changes induced by these regional and teleseismic events.

In addition, the depth resolution of the observed temporal changes from the ambient noise studies are not well understood (Brenguier et al., 2008b; Xu and Song, 2009; Sleep, 2009). Based on the correlations between the temporal changes, non-volcanic tremor and afterslips, Brenguier et al. (2008b) proposed that the temporal changes associated with the 2004 Parkfield earthquake are related to postseismic relaxation in the deeper part of the fault zone and surrounding region. In comparison, Sleep (2009) suggested that the temporal changes observed by Brenguier et al. (2008b) could also be explained by the rock damage in the near surface layers (e.g., Rubinstein and Beroza, 2005). Systematic studies of the sensitivity kernels of the obtained NCCFs (e.g., Pacheco and Snieder, 2006) and the frequency dependent effects of the temporal changes (e.g., Xu and Song, 2009) could help to provide further constraints on the depth extent of the observed temporal changes. Finally, it is possible that the temporal changes are transient, and only occur during the large-amplitude waves, followed by near-instantaneous recovery (e.g., Wu et al., 2010). If so, one has to rely on highly repeatable controlled sources (e.g., Niu et al., 2008) to provide enough temporal samplings before and after the passage of large-amplitude surface waves.

Cross-correlation of seismic noises has become a useful tool for monitoring temporal changes around active fault zones and volcanic regions (e.g., Brenguier et al., 2008a, b). Although our current analysis procedure does not identify any clear temporal changes around the Parkfield section of the SAF associated with four regional and teleseismic events, we feel that with future development it still has the potential of detecting weak temporal changes associated with distant sources.

Acknowledgements The data used in this study come from the High Resolution Seismic Network (HRSN) operated by Berkeley Seismological Laboratory, University of California, Berkeley and are distributed by the Northern California Earthquake Data Center (NCEDC). We thank Fenglin Niu for sharing the sliding window cross-correlation code. The manuscript benefited from valuable comments by Chunquan $\mathrm{Wu}$, Kevin Chao and two anonymous reviewers. The study was funded in part by the National Science Foundation of United States under grants EAR-0710959 and EAR-0956051. The third author Karim Ghazi Sabra acknowledges the support of U.S. Air Force Research Laboratory under grant FA8718-07-186 C-0005 and Dr. Peter Gerstoft.

\section{References}

Audet P (2010). Short note temporal variations in crustal scattering structure near Parkfield California, using receiver functions. Bull Seismol Soc Am 100: $1356-1$ 362, doi:10.1785/ 0120090299.

Bakun W H (1984). Seismic moments, local magnitudes, and coda-duration magnitudes for earthquakes in central California. Bull Seismol Soc Am 74: 439-458.

Bakun W H and Lindh A G (1985). The Parkfield, California, earthquake prediction experiment. Science 229: 619-624.

Brenguier F, Shapiro N M, Campillo M, Ferrazzini V, Duputel Z, Coutant O and Nercessian A (2008a). Towards forecasting volcanic eruptions using seismic noise. Nature Geoscience 1: 126-130, doi:10.1038/ngeo104.

Brenguier F, Campillo M, Hadziioannou C, Shapiro N M, Nadeau R M and Larose E (2008b). Postseismic relaxation along the San Andreas fault at Parkfield from continuous seismological observations. Science 321: 1478-1 481.

Brodsky E E, Roeloffs E, Woodcock D, Gall I and Manga M (2003). A mechanism for sustained ground water pressure changes induced by distant earthquakes. J Geophys Res 108(B8): 2390, doi:10.1029/2002JB002321.

Chao K and Peng Z (2009). Temporal changes of shear wave velocity and anisotropy in the shallow crust induced by the 10/22/1999 M6.4 Chia-Yi, Taiwan, earthquake. Geophys J Int 179: 1 800-1 816, doi:10.1111/j.1365-246X.2009.04384.x.

Chen J H, Froment B, Liu Q Y and Campillo M (2010). Distribution of seismic wave speed changes associated with the 12 May $2008 M_{\mathrm{W}} 7.9$ Wenchuan earthquake. Geophys Res Lett 37: L18302, doi:10.1029/2010GL044582.

Cheng X, Niu F and Wang B (2010). Coseismic velocity change in the rupture zone of the $2008 M_{\mathrm{W}} 7.9$ Wenchuan earthquake observed from ambient seismic noise data. Bull Seismol Soc Am 100(5B), doi: 10.1785/0120090329.

Gerstoft P, Sabra K G, Roux P, Kuperman W A and Fehler M C (2006). Green's functions extraction and surface-wave tomography from microseisms in southern California. Geophysics 71: SI23-SI31.

Gomberg J, Reasenberg P, Bodin P and Harris R (2001). Earthquake triggering by transient seismic waves following the Landers and Hector Mine, California earthquakes. Nature 411: 462-466.

Gomberg J, Bodin P, Larson K and Dragert H (2004). The fundamental process of earthquake nucleation by transient deformations revealed by the M7.9 Denali, Alaska earthquake. Nature 427: 621-624.

Gomberg J, Rubinstein J L, Peng Z, Creager K C and Vidale J E (2008). Widespread triggering of non-volcanic tremor in 
California. Science 319: 173, doi:10.1126/science.1149164.

Guilhem A, Peng Z and Nadeau R M (2010). High-frequency identification of non-volcanic tremor along the San Andreas Fault triggered by regional earthquakes. Geophys Res Lett 37: L16309, doi:10.1029/2010GL044660.

Hadziioannou C, Larose E, Coutant O, Roux P and Campillo M (2009). Stability of monitoring weak changes in multiply scattering media with ambient noise correlation: laboratory experiments. $J$ Acoust Soc Am 125(6): 3 688-3 695.

Hickman S, Zoback M D and Ellsworth W (2004). Introduction to special section: Preparing for the San Andreas Fault Observatory at Depth. Geophys Res Lett 31: L12S01, doi:10.1029/ 2004GL020688.

Hill D P, Reasenberg P A, Michael A, Arabaz W J, Beroza G, Brumbaugh D, Brune J N, Castro R, Davis S and Depolo D (1993). Seismicity remotely triggered by the magnitude 7.3 Landers, California, earthquake. Science 260: 1617-1 623.

Hill D P and Prejean S G (2007). Dynamic triggering. In: Schubert G ed. Treatise on Geophysics. Vol. 4: Earthquake Seismology. Elsevier, Amsterdam, 257-292.

Hough S E and Kanamori H (2002). Source properties of earthquakes near the Salton Sea triggered by the 16 October 1999 M7.1 Hector Mine, California, earthquake. Bull Seismol Soc Am 92: 1281-1 289, doi:10.1785/0120000910.

Jiang T, Peng Z, Wang W and Chen Q F (2010). Remotely triggered seismicity in Continental China by the $2008 M_{\mathrm{W}} 7.9$ Wenchuan earthquake. Bull Seismol Soc Am 100(5B), doi: $10.1785 / 0120090286$.

Johnson P A and Jia X (2005). Non-linear dynamics, granular media and dynamic earthquake triggering. Nature 473: 871-874.

Kanamori H (1977). The energy release in great earthquakes. $J$ Geophys Res 82: 2 981-2 988.

Lee W H K, Bennett R E and Meagher K L (1972). A method of estimating magnitude of local earthquakes from signal duration. US Geol Surv Open-File Rept, 22 pp.

Li Y-G, Chen P, Cochran E S, Vidale J E and Burdette T (2006). Seismic evidence for rock damage and healing on the San Andreas fault associated with the 2004 M6.0 Parkfield earthquake. Bull Seismol Soc Am 96: 349-363.

Li Y-G, Vidale J E, Aki K, Xu F and Burdette T (1998). Evidence of shallow fault zone strengthening after the 1992 M7.5 Landers, California, earthquake. Science 279: 217-219.

Liu Y, Teng T-L and Ben-Zion Y (2004). Systematic analysis of shear-wave splitting in the aftershock zone of the 1999 Chi-Chi earthquake: Shallow crustal anisotropy and lack of precursory variations. Bull Seismol Soc Am 94: 2 330-2 347.

Lengliné $O$ and Marsan D (2009). Inferring the coseismic and postseismic stress changes caused by the $2004 M_{\mathrm{W}}=6$ Parkfield earthquake from variations of recurrence times of microearthquakes. J Geophys Res 114: B10303, doi:10.1029/ 2008JB006118.

Manga M and Brodsky E (2006). Seismic triggering of eruptions in the far field: Volcanoes and geysers. Annu Rev Earth Planet Sci 34: 263-291.

Manga M and Wang C-Y (2007). Earthquake hydrology. In: Schubert G ed. Treatise on Geophysics 4. Elsevier Science,
Amsterdam, 293-320.

Marzorati S and Bindi D (2008). Characteristics of ambient noise cross correlations in northern Italy within the frequency range of 0.1-0.6 Hz. Bull Seismol Soc Am 98: 1 389-1 398, doi:10.1785/0120070140.

Matsumoto S, Obara K, Yoshimoto K, Saito T, Ito A and Hasegawa A (2001). Temporal change in P-wave scatterer distribution associated with the M6.1 earthquake near Iwate volcano, northeastern Japan. Geophys J Int 145: 48-58.

Miyazawa M and Brodsky E E (2008). Deep low-frequency tremor that correlates with the passing surface waves. $J$ Geophys Res 113: B01307, doi:10.1029/2006JB004890.

Miyazawa M, Brodsky E E and Mori J (2008). Learning from dynamic triggering of low-frequency tremor in subduction zones. Earth Planets Space 60: e17-e20.

Mogi K (1979). Global variations of seismic activity. Tectonophysics 57: T43-T50.

Nadeau R M and Guilhem A (2009). Nonvolcanic tremor and the 2003 San Simeon and 2004 Parkfield, California earthquakes. Science 325: 191-193.

Niu F, Silver P G, Daley T, Cheng X and Majer E (2008). Prerupture dilatancy observed from active source monitoring at the Parkfield SAFOD drill site. Nature 454, doi:10.1038/ nature 07111 .

Niu F, Silver P G, Nadeau R M and McEvilly T V (2003). Stress-induced migration of seismic scatterers associated with the 1993 Parkfield aseismic transient event. Nature 426: 544-548.

Ohmi S, Hirahara K, Wada H and Ito K (2008). Temporal variations of crustal structure in the source region of the 2007 Noto Hanto Earthquake, central Japan, with passive image interferometry. Earth Planets Space 60: 1069-1 074.

Pacheco C and Snieder R (2006). Time-lapse traveltime change of single scattered acoustic waves. Geophys J Int 165: 485-500.

Parsons T (2002). Global Omori law decay of triggered earthquakes: Large aftershocks outside the classical aftershock zone. J Geophys Res 107(B9): 2 199, doi:10.1029/2001JB000646.

Peng Z and Ben-Zion Y (2005). Spatiotemporal variations of crustal anisotropy from similar events in aftershocks of the 1999 M7.4 İzmit and M7.1 Düzce, Turkey, earthquake sequences. Geophys J Int 160: 1 027-1 043.

Peng Z and Ben-Zion Y (2006). Temporal changes of shallow seismic velocity around the Karadere-Duzce branch of the North Anatolian fault and strong ground motion. Pure Appl Geophys 163: 567-599.

Peng Z and Chao K (2008). Non-volcanic tremor beneath the Central Range in Taiwan triggered by the $2001 M_{\mathrm{W}} 7.8$ Kunlun earthquake. Geophys $J$ Int 175: 825-829, doi:10.1111/j.1365-246X.2008.03886.x.

Peng Z, Vidale J E, Creager K C, Rubinstein J L, Gomberg J and Bodin P (2008). Strong tremor near Parkfield, CA excited by the 2002 Denali Fault earthquake. Geophys Res Lett 35: L23305, doi:10.1029/2008GL036080.

Peng Z, Vidale J E, Wech A, Nadeau R M and Creager K C (2009). Remote triggering of tremor along the San Andreas fault in central California. J Geophys Res 114: B00A06, 
doi: $10.1029 / 2008 J B 006049$.

Poupinet G, Ellsworth W L and Frechet J (1984). Monitoring velocity variations in the crust using earthquake doublets: An application to the Calaveras fault, California. J Geophys Res 89(B7): 5 719-5 731.

Prejean S G, Hill D P, Brodsky E E, Hough S E, Johnston M J S, Malone S D, Oppenheimer D H, Pitt A M and Richards-Dinger K B (2004). Remotely triggered seismicity on the United States west coast following the $M_{\mathrm{W}} 7.9$ Denali fault earthquake. Bull Seismol Soc Am 94: 348-359.

Roeloffs R A (1998). Persistent water level changes in a well near Parkfield, California, due to local and distant earthquakes. $J$ Geophys Res 103(B1): 869-890, doi:10.1029/97JB02335.

Rost S and Thomas C (2002). Array seismology: Methods and applications. Rev Geophys 40(3): 1 008, doi:10.1029/2000RG 000100.

Rubinstein J L (2010). Nonlinear strong ground motion in medium magnitude earthquakes near Parkfield, CA. Bull Seismol Soc Am doi:10.1785/0120090396 (in press).

Rubinstein J L and Beroza G C (2004a). Evidence for widespread nonlinear strong ground motion in the $M_{\mathrm{W}} 6.9$ Loma Prieta earthquake. Bull Seismol Soc Am 94: 1595-1 608.

Rubinstein J L and Beroza G C (2004b). Nonlinear strong ground motion in the $M_{\mathrm{L}} 5.4$ Chittenden earthquake: Evidence that preexisting damage increases susceptibility to further damage. Geophys Res Lett 31: L23614, doi:10.1029/2004GL021357.

Rubinstein J L and Beroza G C (2005). Depth constraints on nonlinear strong ground motion from the 2004 Parkfield earthquake. Geophys Res Lett 32: L14313, doi:10.1029/ 2005 GL023189.

Rubinstein J L, Uchida N and Beroza G C (2007a). Seismic velocity reductions caused by the 2003 Tokachi-Oki earthquake. J Geophys Res 112: B05315, doi:10.1029/2006JB004440.

Rubinstein J L, Vidale J E, Gomberg J, Bodin P, Creager K C and Malone S D (2007b). Non-volcanic tremor driven by large transient shear stresses. Nature 448: 579-582.

Rubinstein J L, Gomberg J, Vidale J E, Wech A G, Kao H, Creager K C and Rogers G (2009). Seismic wave triggering of nonvolcanic tremor, episodic tremor and slip, and earthquakes on Vancouver Island. $J$ Geophys Res 114: B00A01, doi:10.1029/2008JB005875.

Sabra K G, Gerstoft P, Roux P, Kuperman W A and Fehler M C (2005a). Extracting time-domain Green's function estimates from ambient seismic noise. Geophys Res Lett 32: L03310, doi:10.1029/2004GL021862.

Sabra K G, Gerstoft P, Roux P, Kuperman W A and Fehler M C (2005b). Surface wave tomography from microseisms in Southern California. Geophys Res Lett 32: L14311, doi:10.1029/2005GL023155.

Sabra K G, Roux P, Gerstoft P, Kuperman W A and Fehler M (2006). Extracting coherent coda arrivals from crosscorrelations of long period seismic waves during the Mount St. Helens 2004 eruption. Geophys Res Lett 33: L06313, doi:10.1029/2005GL025563.

Sawazaki K, Sato H, Nakahara H and Nishimura T (2006). Temporal change in site response caused by earthquake strong motion as revealed from coda spectral ratio measurement.
Geophys Res Lett 33: L21303, doi:10.1029/2006GL027938.

Schaff D P and Beroza G C (2004). Coseismic and postseismic velocity changes measured by repeating earthquakes. $J$ Geophys Res 109: B10302, doi:10.1029/2004JB003011.

Sens-Schönfelder C and Wegler U (2006). Passive image interferometry and seasonal variations of seismic velocities at Merapi Volcano, Indonesia. Geophys Res Lett 33: L21302, doi:10.1029/2006GL027792.

Shapiro N M, Campillo M, Stehly L and Ritzwoller M H (2005). High-resolution surface-wave tomography from ambient seismic noise. Science 307: 1615-1 618, doi:10.1126/science. 1108339.

Silver P G, Daley T M, Niu F and Majer E L (2007). Active source monitoring of cross-well seismic travel time for stress-induced changes. Bull Seismol Soc Am 97(1B): 281-293, doi:10.1785/0120060120.

Snieder R, Grêt A, Douma H and Scales J (2002). Coda wave interferometry for estimating nonlinear behavior in seismic velocity. Science 295: 2253-2 255, doi:10.1126/science.1070015.

Sleep N (2009). Depth of rock damage from strong seismic ground motions near the 2004 Parkfield mainshock. Bull Seismol Soc Am 99(5): 3 067-3 076, doi:10.1785/0120090065.

Taira T, Silver P G, Niu F and Nadeau R M (2008). Detecting seismogenic stress evolution and constraining fault zone rheology in the San Andreas Fault following the 2004 Parkfield earthquake. $J$ Geophys Res 113: B03303, doi:10.1029/2007JB005151.

Taira T, Silver P G, Niu F and Nadeau R M (2009). Seismic evidence for remote triggering of fault-strength changes on the San Andreas fault at Parkfield. Nature 461: 636-640.

TenCate J A, Pasqualini D, Habib S, Heitmann K, Higdon D and Johnson P A (2004). Nonlinear and nonequilibrium dynamics in geomaterials. Phys Rev Lett 93, doi:10.1103/PhysRevLett. 93.065501.

Thurber C H, Zhang H, Waldhauser F, Hardebeck J, Michael A and Eberhart-Phillips D (2006). Three-dimensional compressional wavespeed model, earthquake relocations, and focal mechanisms for the Parkfield, California, region. Bull Seismol Soc Am 96(4B): S38-S49, doi:10.1785/0120050825.

Velasco A A, Hernandez S, Parsons T and Pankow K. (2008). Global ubiquity of dynamic earthquake triggering. Nature Geoscience 1: 375-379, doi:10.1038/ngeo204.

Vidale J E and Li Y (2003). Damage to the shallow Landers fault from the nearby Hector Mine earthquake. Nature 421: 524-526.

Waldhauser F, Ellsworth W L, Schaff D P and Cole A (2004). Streaks, multiplets, and holes: High-resolution spatio-temporal behavior of Parkfield seismicity. Geophys Res Lett 31: L18608, doi:10.1029/2004GL020649.

Wang C, Chia Y, Wang P and Dreger D (2009). Role of S waves and Love waves in coseismic permeability enhancement. Geophys Res Lett 36: L09404, doi:10.1029/2009GL037330.

Wegler U, Nakahara H, Korn M and Shiomi K (2009). Sudden drop of seismic velocity after the $2004 M_{\mathrm{W}} 6.6$ Mid-Niigata earthquake, Japan, observed with passive image interferometry. J Geophys Res 114: B06305, doi:10.1029/2008JB005869. 
Wu C, Peng Z and Ben-Zion Y (2009). Non-linearity and temporal changes of fault zone site response associated with strong ground motion. Geophys J Int 176: 265-278, doi:10.1111/ j.1365-246X.2008.04005.x.

Wu C, Peng Z and Ben-Zion Y (2010). Refined thresholds for nonlinear ground motion and temporal changes of site response associated with medium size earthquakes. Geophys $J$ Int 183: 1 567-1 576, doi:10.1111/j.1365-246X.2010.04704.x.

$\mathrm{Xu} \mathrm{Z} \mathrm{J}$ and Song X (2009). Temporal changes of surface wave velocity associated with major Sumatra earthquakes from ambient noise correlation. Proc Natl Acad Sci USA 106(34): 14207-14212.
Zhang J, Gerstoft P and Shearer P M (2009). High-frequency P-wave seismic noise driven by ocean winds. Geophys Res Lett 36: L09302, doi:10.1029/2009GL037761.

Zhao P and Peng Z (2009). Depth extent of damage zones around the central Calaveras fault from waveform analysis of repeating earthquakes. Geophys J Int 179: 1817-1 830, doi:10.1111/ j.1365-246X.2009.04385.x.

Zhang J, Gerstoft P and Bromirski P D (2010). Pelagic and coastal sources of P-wave microseisms: Generation under tropical cyclones. Geophys Res Lett 37: L15301, doi:10.1029/ 2010 GL044288. 